\title{
The side effects of the COVID-19 pandemic on key public health elements - How the global emergency has changed the acute management of myocardial infarction and stroke, the network of cancer care, and assistance to frail individuals
}

\author{
Gabriele Cioni, ${ }^{1}$ Jessica Canini ${ }^{2}$ \\ ${ }^{1}$ Emergency Medicine, SS Cosma and Damiano Hospital, Usl Toscana Centro; ${ }^{2}$ S. Luca Hospital, Usl Toscana Nord-Ovest, \\ Lucca, Italy
}

\begin{abstract}
The coronavirus disease 2019 (COVID-19) pandemic is a primary health problem globally. In particular, it has caused troubles even to the advanced health systems of Western countrieswho attempted to limit the spread of the infection and manage patients with severe respiratory distress. However, this sudden contingency has had a much higher cost if we also consider the cost of suspending ordinary clinical care or delays in the emergency pathways of non-COVID-19 patients. Furthermore, the policies applied to contain the contagion have exacerbated the socio-economic disparities of the population and isolated fragile patients, making them subject to clinical relapses or aggravation of chronic diseases. For this reason, the various specialist centers have equipped themselves to guarantee an effective therapeutic path. In this brief review, we have outlined some consequent repercussions on the management of acute and chronic cardiovascular and neurovascular diseases and on oncological treatment. In particular, we have described the effects of the current health reorganization on some acute and time-dependent diseases, such as stroke and acute coronary syndromes, in which therapeutic delay is potentially disabling or fatal. Furthermore, we have focused on cancer treatments, whose essential cornerstones are early screening and follow-up. Finally, the suffering of the local health network has led to a lack of continuity of care in fragile patients, such as psychiatric, marginalized, or multiple comorbid patients.
\end{abstract}

\section{Introduction}

Since March 2020, a severe acute respiratory syndrome-related coronavirus 2 (SARS-CoV-2) pandemic has spread to involve hundreds of thousands of people

Correspondence: Gabriele Cioni, Emergency Medicine, SS Cosma and Damiano Hospital, Usl Toscana Centro, via sarzanese 4879, 55100 Lucca, Italy.

E-mail: gabrielec.83@gmail.com

Key words: Stroke; oncological care; cardiological care; COVID-19.

Conflict of interests: the authors declare no potential conflict of interests.

Received for publication: 8 January 2021.

Revision received: 22 February 2021.

Accepted for publication: 23 February 2021.

This work is licensed under a Creative Commons Attribution NonCommercial 4.0 License (CC BY-NC 4.0).

${ }^{\circ}$ Copyright: the Author(s), 2021

Licensee PAGEPress, Italy

Italian Journal of Medicine 2021; 15:154-159

doi:10.4081/itjm.2021.1462 around the world, putting even the most advanced and organized health systems in serious difficulty, ${ }^{1}$ in particular, due to the high incidence of hospitalization, especially for frail and elderly patients, with long hospital stays and a significant commitment of resources and health personnel. ${ }^{2}$

Infection containment policies have been a critical element in the fight against the virus, considering the absence of specific therapies. ${ }^{2}$

All measures contained in the 'social distancing' definition have been designed to limit interpersonal contacts as much as possible, isolate patients with COVID-19, and protect those at risk of complications. ${ }^{3}$ However, the negative consequences of these measures have not been equally distributed among the different social categories and types of population. ${ }^{4}$ In addition, aggressive containment measures introduced in many countries have impacted the global economy by triggering health policy consequences that have not yet been fully delineated. ${ }^{5}$

Moreover, the priority given to the management of COVID-19 patients significantly penalized routine care for chronic diseases or emergency pathways in non-COVID-19 patients.

In this brief review, we have collected the primary studies and reviews related to the data indirectly associated with the COVID-19 pandemic regarding social 
costs for marginalized subjects and penalization of chronic care and follow-up of patients with multiple comorbidities.

For these subjects, the lack of regular clinical monitoring could trigger an increase in disease exacerbations and, consequently, hospitalizations, with an overload of the health system. In addition, marginalized subjects risk being left out of the care network, arriving to the hospital already in compromised clinical conditions.

Furthermore, delayed inpatient treatment for acute cardiac or neurological symptoms considerably reduces therapeutic options, leading to a high risk of mortality and disability.

\begin{abstract}
Aim
In this brief review, we have outlined some consequent repercussions on the management of acute and chronic cardiovascular diseases and oncological care.

In particular, we investigated the effects of the current healthcare reorganization on acute and time-dependent diseases, such as stroke and acute coronary syndromes, in which the delay is potentially disabling or lethal. In addition, we have focused on oncological treatments, whose essential cornerstones are precisely early screening and regular follow-up. Moreover, the suffering of the territorial health care network has led to the lack of continuity of care in fragile patients, such as psychiatric, marginalized, or multiple comorbid patients.
\end{abstract}

\section{Effect of social containment on frail and marginalized subjects}

If, on the one hand, the measures of social containment have contributed to stem the pandemic, despite the lack of uniformity among the various countries involved, on the other hand, they have increased the isolation and fragility of the weakest and most marginalized categories.

The precariousness of the clinical conditions of fragile and marginalized subjects is very diversified.

A percentage of homeless people suffer from chronic illnesses and mental disorders that escape routine health surveillance and are not adequately included in epidemiological monitoring systems or housed in quarantine and isolation facilities. ${ }^{6}$

Similar considerations can be made for inmates, whose quality of life is absolutely different between states, and recent reports denounce high levels of contagion, high prevalence of chronic diseases, and increased mortality in detention centers. ${ }^{7}$

Equally precarious are the conditions of refugees, immigrants, that is, subject to the limits of society for which only little clinical assistance is provided, or there is no assistance at all. ${ }^{8}$ Furthermore, the elderly, who represent a category at risk for the development of complications of SARS-CoV-2 infection, and who have therefore been the main object of social isolation and containment measures, are also psychologically fragile subjects, mostly excluded from the forms of digital socialization, prone to depressive pathologies and therefore easy to abandon chronic therapies. ${ }^{9,10}$

The pandemic has also significantly affected the management of psychiatric patients, reducing the effectiveness of health services that treat chronic care, aggravating their psychological balance, and loosening social and interpersonal relationships, with a consequent increase in access to the emergency room for episodes of acute agitation. ${ }^{11-13}$

Furthermore, these individuals' limited access to health information could make them difficult to protect, undermining efforts to contain the pandemic.

\section{Oncologist care system}

Neoplastic pathology is the second leading cause of death globally, with approximately 9.6 million annual deaths in 2018; the main results in terms of mortality reduction were obtained through the implementation of prevention, improvement of early diagnosis, and treatments..$^{14,15}$ Therefore, the impact of the pandemic was highly relevant in the management of cancer patient, altering the administration and planning of cancer treatments.

Despite the importance of constant contact between patients and reference specialists, pandemic containment measures have forced various health systems to restrict access to hospitals for outpatient visits and thus making adequate clinical instrumental follow-up more difficult. As a result, the possibility of contagion of the cancer patient in the hospital setting is significant, with a value of $28.6 \%$ in some reports. ${ }^{16}$

The immunosuppressed oncologic patient is considered at high risk ${ }^{17}$ for developing life-threatening complications related to COVID-19. ${ }^{18,19}$

Moreover, oncological therapies, such as chemotherapy, targeted therapy, radiotherapy, and immunotherapy, could expose the patient to prolonged immunosuppression, making the subject more vulnerable to infection and its complications. However, modification of therapeutic regimens could impair the response to the oncological disease.

The main data on cancer patients also affected by COVID-19 were collected on the Chinese population; patients with oncological disease affected by SARS$\mathrm{CoV}-2$ were $1 \%$, with a mortality of $5.6 \%$ compared to $2.3 \%$ in the general population, ${ }^{16}$ data that agree with the increase in mortality also reported in other countries. $^{20}$

Therefore, oncologists have deeply and quickly re- 
organized their care systems and treatment schemes. ${ }^{18}$ The protection of healthcare professionals and patients themselves is the first step towards continuity of care. ${ }^{21}$ To achieve this, in addition to the universally widespread sanitation measures, ${ }^{22}$ many hospitals have encouraged telemedicine and reduced the duration of hospitalizations, when possible, avoiding unnecessary imaging and consultations.

According to data from a recent multicenter observational study ${ }^{23}$ physical examination was not performed in asymptomatic patients in $76.2 \%$ of centers, sometimes substituted for a targeted examination in the presence of known metastases. Furthermore, blood pressure control was not routinely performed in $90.5 \%$ of centers. In addition, blood sampling requirements and computed tomography control to monitor tumor response to therapy were also reduced.

The management of hospitalized patients has also been significantly revolutionized..$^{23}$ In particular, this led to a reduction in palliative care admissions in 50\% of the centers, and chemotherapy was performed in daytime hospitalization only in $25 \%$ of the centers. In addition, no indication was given to intensive care for the terminally ill in $47.6 \%$ of the centers. However, most hospitalizations occurred only in COVID-19 negative patients, or, in any case, after performing nasopharyngeal swabs.

The pandemic has profoundly affected the entire cancer community, ${ }^{24}$ not just patients or the care network, but also research organizations, study groups, and collaboration networks between specialists. ${ }^{18}$ In most cases, the multidisciplinary meetings took place by videoconference, while only a small part was held in the presence of the health personnel in respect of social distances. ${ }^{23}$

Although the variations in the incidence of neoplastic diseases due to the economic recession from COVID-19 will only be seen in the near future, the previous recessions have had a profound fallout in terms of reduced prevention and early diagnosis, and less access to treatment, mainly due to the effects of unemployment. ${ }^{25}$

\section{Cardiological care of acute coronary syndromes during COVID-19}

Data from the first studies ${ }^{26}$ conducted on the Chinese population indicate that patients with cardiovascular diseases, such as hypertension, diabetes, and pre-existing coronary heart disease, showed a worse prognosis and higher mortality rates. In particular, COVID-19 patients with early myocardial involvement had shown a higher frequency of organ compromise, with severe lung involvement and the need for invasive ventilation, rapid deterioration of renal function, ${ }^{27,28}$ up to very high in-hospital mortality, com- pared to non-hospital COVID-19 subjects. In addition, elevation in high sensitive troponin levels was associated with very high in-hospital mortality, showing that heart damage is an important prognostic marker. ${ }^{28}$

The abrupt reorganization of health resources to deal with the pandemic has upset the routine and emergency care programs of non-COVID-19 cardiac patients. In particular, significant critical issues were recorded due to the growing demand for healthcare personnel dedicated to the management of COVID-19 patients, the priority use of ventilators, and the need for intensive care beds. ${ }^{29}$ Due to the consequent shortage of staff committed to addressing the emerging pandemic and reducing the risk of possible contacts with SARS$\mathrm{CoV}-2$ of hospitalized patients, procedures and elective visits have been postponed, and the threshold for the indication for hospitalization or an invasive procedure has risen. Reductions in hospitalizations for acute coronary syndromes have been described globally, although detailed reports are still absent. ${ }^{30}$

Also, due to the risk of cath lab staff infection, the ability to perform urgent $\mathrm{PCI}$ has been limited in many centers and reserved for patients with STEMI (ST-elevation myocardial infarction) or highly unstable. In some centers, thrombolysis has been considered the first choice for STEMI. In addition, due to the understandable reluctance to go to emergency facilities for fear of contagion, relevant clinical conditions are diagnosed late, and compliance with life-saving therapies is also at risk. ${ }^{29}$

Data collected in the first phase of the pandemic (i.e., in the first 4 weeks from $27^{\text {th }}$ February 2020) from the Italian reality, a country heavily affected by COVID-19, showed a decrease in percutaneous coronary angioplasty $(\mathrm{PCI})$ procedures for acute coronary syndrome (ACS) by $32 \%$, with a peak of $50 \%$ in the last two weeks of the analyzed period. ${ }^{31}$ Similar results were described in a retrospective study conducted in a third-level hospital in Germany, demonstrating a significant reduction in admissions for ACS, as well as cardiac catheterization and PCI procedures, from January to June 2020 , compared to a similar period of 2019 and $2018 .{ }^{32}$ The causes of this trend can be many and are still under investigation; however, the most worrying and repeatedly reported phenomenon is the failure to seek medical attention ${ }^{33-35}$ promptly. In terms of the incidence of post-infarct heart failure and arrhythmic disorders, the effects of this trend on public health will be visible in the near future. ${ }^{36,37}$

\section{Stroke acute care during COVID-19 pandemic}

The possibility of a rapid evaluation in the emergency room is an essential prerogative for effective treatment in case of stroke, which is known to be a highly time-dependent disease. Delays are associated 
with a poor prognosis and a high risk of disabling outcomes. ${ }^{38}$ Unfortunately, as with other conditions, the current pandemic has severely reduced the possibility of urgent medical evaluation for stroke.

In a retrospective study conducted in Norway, the authors reported a significant decrease in hospitalizations for stroke (ischemic or hemorrhagic) and transient ischemic attacks in the first weeks of lockdown for the current pandemic, compared to a similar previous period; ${ }^{38}$ consequently, the number of systemic thrombolysis was also reduced. Thus, some of the possible causes of the failure to request medical intervention would absolutely not reside in the modification of hospital admission criteria or election criteria for thrombolysis, but rather in the general population which, unable to readily recognize stroke symptoms, is more willing to wait - and - see attitude, misunderstanding the importance of acute treatment. ${ }^{39-41}$

Some factors previously known to contribute to the delay in diagnosis, especially social isolation, may have been aggravated by the current pandemic. ${ }^{41-44}$

With regard to the Italian reality, ${ }^{45}$ the pathways for the management of acute stroke have been redesigned to give priority to SARS-CoV-2 patients: health personnel has been largely relocated and many departments converted to the exclusive management of the COVID-19 $9^{46}$ patient. ${ }^{47,48}$

The number of Stroke Centers has been significantly reduced, requiring the centralization of many patients from large areas in a small number of hospitals..$^{45,47,48}$

A significant example is given by the Lombardy Region, in which the Stroke centers have been reduced from 36 to 11. Considering the difficulty in completely separating the clinical pathways between COVID-19 and not, all patients were considered suspicious and the brain diagnostics integrated with pulmonary diagnostics. The shortage of medical personnel has forcibly reduced the possibility of obtaining specialist consultations; second-level instrumental examinations, such as magnetic resonance and angiography, were limited due to the need to contain the contagion.

The main relapse of this reorganization was the lengthening of the stroke times and the delayed administration of thrombolytics. ${ }^{49}$

Similarly to data from other European countries, in particular France and Germany, many of the Italian Stroke Centers reported a reduction of about $26-30 \%$ hospitalization rate for minor stroke and transient ischemic attack (TIA); reduced acute drug treatment by $50 \%$ compared to $2019 .{ }^{45}$

The consequences of these changes, associated with the reduction of follow-up and rehabilitation services, despite the activation of telemedicine and alternative services, will be evident shortly; predictable long-term effects, in terms of disability and mortality secondary to hypo- or delayed treatment, have been highlighted in previous studies. ${ }^{50,51}$

\section{Conclusions}

The management of the current pandemic has absorbed most resources and health personnel, forcing several health systems to review management protocols for COVID-19 and non-COVID-19 patients. Considerable efforts have been made to ensure the safety of staff and patients, sometimes to the detriment of continuity of care. The first results of such a radical change are only partial, and the actual cost in health and social terms will only be quantifiable in the future and perhaps will last for years.

\section{References}

1. Worldometers.info.2020. COVID-19 coronavirus pandemic. Available from: https://www.worldometers.info/ coronavirus/

2. Cossarizza A, De Biasi S, Guaraldi G, et al. COVID-19 working, SARS-CoV-2, the virus that causes COVID19: cytometry and the new challenge for global health. Cytometry A 2020 [Epub ahead of print].

3. European Centre for Disease Prevention and Control (ECDC). Considerations relating to social distancing measures in response to COVID-19 - Second update. ECDC; Stockholm: 2020.

4. Xiao H, Zhang Y, Kong D, et al. Social capital and sleep quality in individuals who self-isolated for 14 days during the coronavirus disease 2019 (COVID-19) outbreak in January 2020 in China. Med Sci Monit 2020;26 [Epub ahead of print].

5. Cornwall W. Can you put a price on COVID-19 options? Experts weigh lives versus economics. Science 2020. [Epub ahead of print].

6. Tsai WM. COVID-19: a potential public health problem for homeless populations. Lancet Public Health 2020 [Epub ahead of print].

7. Kinner SA, Young JT, Snow K, et al. Prisons and custodial settings are part of a comprehensive response to COVID19. Lancet Public Health 2020 [Epub ahead of print].

8. Daniels JP. Venezuelan migrants 'struggling to survive' amid COVID-19. Lancet 2020;395:1023.

9. Yang Y, Li W, Zhang Q, et al. Mental health services for older adults in China during the COVID-19 outbreak. Lancet Psychiatry 2020;7 [Epub ahead of print].

10. Kuwahara KK, Fukuda Y. COVID-19: Active measures to support community-dwelling older adults. Travel Med Infect Dis 2020 [Epub ahead of print].

11. Bojdani E, Rajagopalan A, Chen A, et al. COVID-19 Pandemic: Impact on psychiatric care in the United States. Psychiatry Res 2020;289:113069. [Epub ahead of print].

12. Cui LB, Wang XH, Wang HN. Challenges facing coronavirus disease 2019: Psychiatric services for patients with mental disorders. Psychiatry Clin Neurosci 2020 [Epub ahead of print]. 
13. Percudani M, Corradin M, Moreno M, et al. Mental health services in Lombardy during COVID-19 outbreak. Psychiatry Res 2020;288 [Epub ahead of print].

14. Bray F, Ferlay J, Soerjomataram I, et al. Global cancer statistics 2018: GLOBOCAN estimates of incidence and mortality worldwide for 36 cancers in 185 countries. Cancer J Clin 2018;68:394-424.

15. Ward EM, Sherman RL, Henley SJ, et al. Annual report to the nation on the status of cancer, featuring cancer in men and women age 20-49 years. J Nat Cancer Instit 2019;111:1279-97.

16. Zhang L, Zhu F, Xie L, et al. Clinical characteristics of COVID-19-infected cancer patients: a retrospective case study in three hospitals within Wuhan, China. Ann Oncol 2020;31:894-901.

17. World Health Organization. Report of the WHO-China Joint Mission on coronavirus disease 2019 (COVID-19). Significant account of fatality rates and comorbidities in reports from China related to COVID-19 infection. Geneva: WHO; 2020.

18. The Lancet Oncology. COVID-19: global consequences for oncology. Lancet Oncol 2020;21:467.

19. Asokan I, Rabadia SV, Yang EH. The COVID-19 pandemic and its impact on the cardio-oncology population. Curr Oncol Rep 2020;22:60.

20. Baud D, Qi X, Nielsen-Saines K, et al. Real estimates of mortality following COVID-19 infection. Lancet Infect Dis 2020 [Epub ahead of print].

21. Rusthoven CG, Yamamoto M, Bernhardt D, et al. Evaluation of first-line radiosurgery vs whole-brain radiotherapy for small cell lung cancer brain metastases: the FIRE-SCLC cohort study. JAMA Oncol 2020;6:1028-37.

22. Hellewell J, Abbott S, Gimma A, et al. Feasibility of controlling COVID-19 outbreaks by isolation of cases and contacts. Lancet Glob Health 2020;8:e488-96.

23. Onesti CE, Rugo HS, Generali D, et al. Oncological care organisation during COVID-19 outbreak. ESMO Open 2020;5:e000853.

24. Burki TK. Cancer guidelines during the COVID-19 pandemic. Lancet Oncol 2020;21:629-30.

25. Gomez SL, Canchola AJ, Nelson DO, et al. Recent declines in cancer incidence: related to the Great Recession? Cancer Causes Control 2017;28:145-54.

26. Zhou F, Yu T, Du R, et al. Clinical course and risk factors for mortality of adult inpatients with COVID-19 in Wuhan, China: a retrospective cohort study. Lancet 2020;395:1054-62.

27. Shi S, Qin M, Shen B, et al. Association of cardiac injury with mortality in hospitalized patients with COVID-19 in Wuhan, China. JAMA Cardiol 2020 Mar 25. [Epub ahead of print].

28. Guo T, Fan Y, Chen M, et al. Cardiovascular implications of fatal outcomes of patients with coronavirus disease 2019 (COVID-19). JAMA Cardiol 2020 Mar 27. [Epub ahead of print].

29. Everaert BR, Muylle J, Twickler TB. Emerging cardiological issues during the COVID-19 pandemic. Eur J Clin Invest 2020;50:e13270.

30. Wood S. The mystery of the missing STEMIs during the COVID-19 pandemic. tctMD. April 2, 2020. Availble from: https://www.tctmd.com/news/mystery-missingstemis-during-covid-19-pandemic Accessed: April 3, 2020.
31. Piccolo R, Bruzzese D, Mauro C, et al. Population trends in rates of percutaneous coronary revascularization for acute coronary syndromes associated with the COVID-19 Outbreak. Circulation 2020;141:2035-7.

32. Vacanti G, Bramlage P, Schymik G, et al. Reduced rate of admissions for acute coronary syndromes during the COVID-19 pandemic: an observational analysis from a tertiary hospital in Germany. Observational Study Herz 2020;45:663-7.

33. De Rosa S, Spaccarotella C, Basso C, et al.; Società Italiana di Cardiologia and the CCU Academy investigators group. Reduction of hospitalizations for myocardial infarction in Italy in the COVID-19 era. Eur Heart J 2020;41:2083-8.

34. Böhm M, Frey N, Giannitsis E, et al. Coronavirus disease 2019 (COVID-19) and its implications for cardiovascular care: expert document from the German Cardiac Society and the World Heart Federation. Clin Res Cardiol 2020;109:1446-59.

35. Katz JN, Sinha SS, Alviar CL, et al. COVID-19 and disruptive modifications to cardiac critical care delivery: JACC review topic of the week. J Am Coll Cardiol 2020;76:72-84.

36. Scholz KH, Maier SKG, Maier LS, et al. Impact of treatment delay on mortality in ST-segment elevation myocardial infarction (STEMI) patients presenting with and without haemodynamic instability: results from the German prospective, multicentre FITT-STEMI trial. Eur Heart J 2018;39:1065-74.

37. Zhang B, Shen DP, Zhou XC, et al. Long-term prognosis of patients with acute non-ST-segment elevation myocardial infarction undergoing different treatment strategies. Chin Med J (Engl) 2015;128:1026-31.

38. Kristoffersen ES, Jahr SH, Thommessen B, Rønning OM. Effect of COVID-19 pandemic on stroke admission rates in a Norwegian population. Acta Neurol Scand 2020;142:632-6.

39. Lecouturier J, Murtagh MJ, Thomson RG, et al. Response to symptoms of stroke in the UK: a systematic review. BMC Health Serv Res 2010;10:157.

40. Teuschl Y, Brainin M. Stroke education: discrepancies among factors influencing prehospital delay and stroke knowledge. Int J Stroke 2010;5:187-208.

41. Le Bonniec A, Haesebaert J, Derex L, et al. Why patients delay their first contact with health services after stroke? A qualitative focus group-based study. PLoS One 2016;11:e0156933.

42. Faiz KW, Sundseth A, Thommessen B, et al. Factors related to decision delay in acute stroke. J Stroke Cerebrovasc Dis 2014;23:534-9.

43. Jorgensen HS, Nakayama H, Reith J, et al. Factors delaying hospital admission in acute stroke: the Copenhagen Stroke Study. Neurology 1996;47:383-7.

44. Wester P, Rådberg J, Lundgren B, et al. Factors associated with delayed admission to hospital and in-hospital delays in acute stroke and TIA: a prospective, multicenter study. Seek- Medical-Attention-in-Time Study Group. Stroke 1999;30:40-8.

45. Bersano A, Kraemer M, Touzé E, et al. Stroke care during the COVID-19 pandemic: experience from three large European countries. Eur J Neurol 2020;27:1794800 .

46. Bersano A, Pantoni L. On being a neurologist in Italy at 
the time of the COVID-19 outbreak. Neurology 2020 [In press].

47. Baracchini C, Pieroni A, Viaro F, et al. Acute stroke management pathway during coronavirus-19 pandemic. Neurol Sci 2020 [Epub ahead of print].

48. Caso V, Federico A. No lockdown for neurological diseases during COVID-19 pandemic infection. Neurol Sci 2020 [Epub ahead of print].

49. Stefanini GG, Azzolini E, Condorelli G. Critical organizational issues for cardiologists in the COVID-19 Out- break: a frontline experience from Milan, Italy. Circulation 2020 [Epub ahead of print].

50. Silvestrelli G, Parnetti L, Paciaroni M, et al. Early admission to stroke unit influences clinical outcome. Eur J Neurol 2006;3:250-5.

51. Lees KR, Bluhmki E, von Kummer R, et al. Time to treatment with intravenous alteplase and outcome in stroke: an updated pooled analysis of ECASS, ATLANTIS, NINDS, and EPITHET trials. Lancet 2010;375:1695-703. 